\title{
A Dynamic Model of Housing Wealth Effect: Based on the Diversity of Wealth Expectations
}

\author{
Danxiao JIAO \\ School of Management, University of Chinese Academy of Sciences, Beijing 100190, China \\ E-mail: jiaodanxiao11@mails.ucas.ac.cn \\ Di WU \\ School of Management, University of Chinese Academy of Sciences, Beijing 100190, China \\ E-mail: diwu@ucas.ac.cn \\ Xiuting LI \\ School of Management, University of Chinese Academy of Sciences, Beijing 100190, China \\ E-mail: lindaall@163.com \\ Jichang DONG \\ School of Management, University of Chinese Academy of Sciences, Beijing 100190, China \\ E-mail: jcdonglc@ucas.ac.cn \\ Desheng Dash WU \\ Risklab, University of Toronto, 19 Borden ST, Toronto, ON, Canada \\ E-mail:dash@risklab.ca
}

Received December 11, 2013, accepted December 18, 2013

Danxiao JIAO is a PhD candidate in the School of Management at University of Chinese Academy of Sciences. Her research interests are mainly in the real estate economics, finance and macroeconomic analysis. She has published many articles in Management Review and other journals.

Di WU is a lecturer in the School of Management at University of Chinese Academy of Sciences. He received his BS in Economics from Beihang University in 2006 and PhD in Management Science and Engineering from Graduate University of Chinese Academy of Sciences in 2011. In 2010, he has sustained by China Scholarship Council to study urban sociology as a join PhD student in University of Chicago. His research interests are mainly in the urban economics, real estate economics and macroeconomic analysis. He has published articles in International Journal of Information Technology \& Decision Making and other journals.

Xiuting LI is a post-doctor in the School of Management at University of Chinese Academy of Sciences. Her research interests are mainly in the real estate economics and macroeconomic analysis. She has published articles in many journals.

Jichang DONG is a professor in the School of Management at University of Chinese Academy of Sciences. He received his PhD in Management Science and Engineering from Institute of Systems Science, Academy of Mathematics and Systems Science, Chinese Academy of Sciences in 2003. His research interests are mainly in the real estate economics, finance and macroeconomic analysis. He has published articles in International Journal of Information Technology \& Decision Making, International Journal of Revenue Management and other journals. 


\begin{abstract}
Considering the dynamics and diversity of wealth expectations, this paper follows and extends Hall's consumption function to establish a new dynamic model of housing wealth effect. People are classified into the rich group and the poor group and a housing wealth effect model is made for each group to explore the relationship between housing wealth effect and social inequality. We get three interesting conclusions which are helpful for further empirical test apart from the former deviation or fallacy.
\end{abstract}

Keywords consumption function; housing wealth effect; dynamic model; diversity; social inequality

\title{
1 Introduction
}

The life cycle-permanent income hypothesis raised by Hall ${ }^{[1]}$ has always been regarded as the theoretical basis for researches of housing wealth effect. And models adopted in housing wealth effect researches are mainly derived from Hall's work.

As a recognized consumption model, Hall's work has been applied and tested repeatedly in the field of housing wealth effect research. However, based on the abundant related studies, we found two significant problems that may result to deviation or fallacy in the conclusion of housing wealth effect analysis.

1) A lot of scholars have considered the housing wealth effect as a static process, but it should be a dynamic process in real life.

According to the classical discussion of Hall, both the rate of subjective time preference $(\delta)$ and the real interest rate $(r)$ are treated as constants. Similarly, recent work about housing wealth effect mostly continued this conception, and regard housing wealth effect as a static process. For example, Carroll etc. ${ }^{[2]}$ and Aron etc. ${ }^{[3]}$, although make some innovations, still treat it as a static process. But in real life, the housing wealth effect should be a dynamic process. Take Hall's work as an example, $\delta$ and $r$ are variables that change with time. Furthermore, $\delta$ is a subjective variable that may change greatly with different people even in the same period according to the intension of Behavioral Economics. In conclusion, the value of housing wealth effect changes not only with time but also with different person, so we believe that housing wealth effect is a dynamic process ${ }^{[4]}$.

2) People's expectations are regarded as the same in the old model, while it doesn't meet the expectation formation of the rich and the poor.

On the basis of Engel's law, the poor and the rich classified by income have different consumer behavior, which is affected by the demand and expectations of the poor and the rich. Generally, we define the different behaviors of the rich and the poor as structural difference ${ }^{[5]}$. Regardless of the structural difference in the formation of housing wealth effect, previous researches have made some general deviations and thus have a poor operability and application value. Therefore, we believe that the estimation of wealth effect must consider the wealth expectation differences brought by the structural differences ${ }^{[6]}$.

Centering on the two problems, we made several improvements and interesting analysis to the pre-existing model. 


\section{Model}

\subsection{Improvements to the consumption function}

According to the hypothesis of Hall ${ }^{[1]}$ that, people always maximize their whole-life utility, we make a model as follows:

$$
\begin{gathered}
\operatorname{Max}_{c_{t}} E_{t} \sum_{\tau=0}^{T-t}\left[\left(1+\delta_{t+\tau}\right)\right]^{-\tau} u\left(c_{t+\tau}\right) \\
\text { s.t. } \sum_{\tau=0}^{T-t}\left(1+r_{t+\tau}\right)^{-\tau}\left(c_{t+\tau}-w_{t+\tau}\right)=A_{t}
\end{gathered}
$$

As by Hall ${ }^{[1]}$, the following notation is used throughout the paper:

$E=$ mathematical expectation conditional on all information available;

$\delta=$ rate of subjective time preference, which changes with time and different person;

$r=$ real interest rate, which changes over time;

$T=$ length of economic life;

$u(\cdot)=$ one-period utility function, strictly concave;

$c=$ consumption;

$w=$ income;

$A=$ wealth assets apart from human capital;

In order to find the optimal solution, we build a Lagrangian equation:

$$
L=E_{t} \sum_{\tau=0}^{T-t}\left[\left(1+\delta_{t+\tau}\right)\right]^{-\tau} u\left(c_{t+\tau}\right)+\lambda\left[\sum_{\tau=0}^{T-t}\left(1+r_{t+\tau}\right)^{-\tau}\left(c_{t+\tau}-w_{t+\tau}\right)-A_{t}\right]
$$

Then, we take partial derivatives of $c_{t}, c_{t+1}, \cdots, c_{T}$ respectively to solve the Lagrangian equation and get the following equations:

$$
\left\{\begin{array}{l}
\frac{\partial L}{\partial c_{t+i}}=E_{t}\left(1+\delta_{t+i}\right)^{-i} u^{\prime}\left(c_{t+i}\right)+\lambda\left(1+r_{t+i}\right)^{-i}=0, \quad i=0,1,2, \cdots, T-t \\
\frac{\partial L}{\partial \lambda}=\sum_{\tau=0}^{T-t}\left(1+r_{t+\tau}\right)^{-\tau}\left(c_{t+\tau}-w_{t+\tau}\right)-A_{t}=0
\end{array}\right.
$$

Solving the first order condition, we can get:

$$
\begin{aligned}
E_{t} u^{\prime}\left(c_{t}\right) & =-\lambda \\
E_{t} u^{\prime}\left(c_{t+1}\right) & =-\lambda \frac{\left(1+r_{t+1}\right)^{-1}}{\left(1+\delta_{t+1}\right)^{-1}} \\
\vdots & \\
E_{t} u^{\prime}\left(c_{t+i}\right) & =-\lambda \frac{\left(1+r_{t+i}\right)^{-i}}{\left(1+\delta_{t+i}\right)^{-i}}
\end{aligned}
$$

Here we assume that $\pi_{i}=\left(\frac{1+r_{t+i}}{1+\delta_{t+i}}\right)^{-i}$, then $E_{t} u^{\prime}\left(c_{t+\tau}\right)=\frac{\pi_{\tau}}{\pi_{\tau-1}} u^{\prime}\left(c_{t+\tau-1}\right)$, and we can easily get that

$$
E_{t} u^{\prime}\left(c_{t+\tau}\right)=\frac{\pi_{\tau}}{1} u^{\prime}\left(c_{t}\right)=\pi_{t} u^{\prime}\left(c_{t}\right)
$$

In order to get the optimal analytical solution, we borrow ideas from Hall ${ }^{[1]}$, and assume that the utility function is a quadratic equation which can be expressed as $u\left(c_{t}\right)=-\frac{1}{2}\left(\bar{c}-c_{t}\right)^{2}$, 
where $\bar{c}$ is the bliss level of consumption. Then we go on to solve the problem using the utility function, and get that:

$$
\begin{aligned}
u^{\prime}\left(c_{t}\right) & =\bar{c}-c_{t} \\
u^{\prime}\left(c_{t+\tau}\right) & =\bar{c}-c_{t+\tau}
\end{aligned}
$$

Taking equation (7) and (8) into equation (6), we get equation (9):

$$
E_{t}\left(\bar{c}-c_{t+\tau}\right)=\pi_{t}\left(\bar{c}-c_{t}\right)
$$

The equation (9) means that $\bar{c}-c_{t+\tau}=\pi_{t}\left(\bar{c}-c_{t}\right)+\varepsilon_{t}$.

By this time, we get the formula of $c_{t+\tau}$, which is

$$
c_{t+\tau}=\left(1-\pi_{t}\right) \bar{c}+\pi_{t} c_{t}-\varepsilon_{t}
$$

Equation (11) is obtained when equation (10) is taken into constraint condition $\sum_{\tau=0}^{T-t}(1+$ $\left.r_{t+\tau}\right)^{-\tau}\left(c_{t+\tau}-w_{t+\tau}\right)=A_{t}$ :

$$
\sum_{\tau=0}^{T-t}\left(1+r_{t+\tau}\right)^{-\tau}\left[\left(1-\pi_{t}\right) \bar{c}+\pi_{t} c_{t}-\varepsilon_{t}-w_{t+\tau}\right]=A_{t}
$$

Assuming $T \rightarrow \infty$, we get consumers' optimization:

$$
c_{t}=\frac{A_{t}}{\sum_{\tau=0}^{\infty}\left[\pi_{t}\left(1+r_{t+\tau}\right)^{-\tau}\right]}+\frac{\sum_{\tau=0}^{\infty}\left[\left(1+r_{t+\tau}\right)^{-\tau} w_{t+\tau}\right]}{\sum_{\tau=0}^{\infty}\left[\pi_{t}\left(1+r_{t+\tau}\right)^{-\tau}\right]}+\frac{\pi_{t} \bar{c}-\bar{c}}{\pi_{t}}+\mu_{t}
$$

Equation (12) is the new consumption function we get. We can easily find that people's consumption depend on their current wealth and lifetime income.

The implications of our new result are presented in one conclusion and one corollary:

Conclusion 1: Coefficient of wealth in the consumption function is a variable one. Current consumption is under the influence of the expected rate of subjective time preference and expected real interest rate.

Corollary 1 Based on our analysis, consumption function can be simplified as follows:

$$
c_{t}=\bar{c}_{0}+f^{0}\left(r_{t}^{e}, \delta_{t}^{e}\right) A_{t}+g^{0}\left(r_{t}^{e}, \delta_{t}^{e}\right) w_{t}+\mu_{t}
$$

Where we assume that $\delta^{e}$ stands for expected rate of subjective time preference, and $r^{e}$ stands for expected real interest rate. At the same time, we assume that $c_{0}=\frac{\pi_{t} \bar{c}-\bar{c}}{\pi_{t}}, f^{0}\left(r_{t}^{e}, \delta_{t}^{e}\right)=$ $\sum_{\tau=0}^{\infty}\left[\pi_{t}\left(1+r_{t+\tau}\right)^{-\tau}\right], g^{0}\left(r_{t}^{e}, \delta_{t}^{e}\right) w_{t}=\frac{\sum_{\tau=0}^{\infty}\left[\left(1+r_{t+\tau}\right)^{-\tau} w_{t+\tau}\right]}{\sum_{\tau=0}^{\infty}\left[\pi_{t}\left(1+r_{t+\tau}\right)^{-\tau}\right]}$.

\subsection{Dynamic model of housing wealth effect}

Here the current wealth is defined only as the housing wealth $H_{t}$. The dynamic model of housing wealth effect is obtained:

$$
c_{t}=\bar{c}_{0}+f^{0}\left(r_{t}^{e}, \delta_{t}^{e}\right) H_{t}+g^{0}\left(r_{t}^{e}, \delta_{t}^{e}\right) w_{t}+\mu_{t}
$$

In our equation, the level of housing wealth effect is measured by $f^{0}\left(r_{t}^{e}, \delta_{t}^{e}\right)$. By taking logarithms of variables, we can highlight the parameters' economic significance and better analyze the relationships between the parameters. Assuming $\ln c_{t}=$ cons $_{t}, \ln H_{t}=$ fpri $_{t}$, $\ln w_{t}=i n c o_{t}$, we take logarithms of both sides of equation (14), and get a new equation:

$$
\text { cons }_{t}=c_{0}+f\left(r_{t}^{e}, \delta_{t}^{e}\right) \text { fpri }_{t}+g\left(r_{t}^{e}, \delta_{t}^{e}\right) \text { inco }_{t}+e_{t}
$$


Dividing both sides of equation (15) by $f p r i t$, we get

$$
\frac{\text { cons }_{t}}{\text { fpri }_{t}}=\frac{c_{0}}{f p r i_{t}}+f\left(r_{t}^{e}, \delta_{t}^{e}\right)+g\left(r_{t}^{e}, \delta_{t}^{e}\right) \frac{i n c O_{t}}{f \text { pri }_{t}}+\frac{e_{t}}{\text { fpri }_{t}}
$$

And then housing wealth effect $f\left(r_{t}^{e}, \delta_{t}^{e}\right)$ can be expressed as:

$$
f\left(r_{t}^{e}, \delta_{t}^{e}\right)=\frac{\text { ons }_{t}}{\text { fprit }}-\frac{c_{0}}{\text { fprit }}-g\left(r_{t}^{e}, \delta_{t}^{e}\right) \frac{\text { incot }_{t}}{\text { fpri }_{t}}-\frac{e_{t}}{f p r i_{t}}
$$

According to equation (17), we get another conclusion:

Conclusion 2: The housing price-to-income ratio $\left(\frac{f p r i_{t}}{i n c o_{t}}\right)$ is a crucial factor in housing wealth effect.

\subsection{Dynamic models of wealth effect for the rich and the poor}

Since people with different incomes have different consumer behaviors, we clarify people into two groups according to their income. Then the housing wealth effect model (15) is transformed into two equations:

$$
\begin{aligned}
& \text { The rich: } \text { cons }_{1 t}=c_{10}+f_{1}\left(r_{1 t}^{e}, \delta_{1 t}^{e}\right) f_{p r i}+g_{1}\left(r_{1 t}^{e}, \delta_{1 t}^{e}\right) \text { inco }_{1 t}+e_{1 t} \\
& \text { The poor: } \text { cons }_{2 t}=c_{20}+f_{2}\left(r_{2 t}^{e}, \delta_{2 t}^{e}\right) \text { fpri }_{t}+g_{2}\left(r_{2 t}^{e}, \delta_{2 t}^{e}\right) \text { inco }_{2 t}+e_{2 t}
\end{aligned}
$$

Former studies related with housing wealth effect equal to (18) plus (19), which hide many problems. For the expectation differences, addition makes lots of opposite effects cancel out. As a result, we should pay more attention to (18) minus (19). In this way, we can find some hidden problems, take economic inequality as an example.

According to the Permanent Income Hypothesis, the Life-cycle Hypothesis and our analysis, under the rationality assumption, people tend to smooth their current consumption based on their lifetime income, and changes in current income have little influence on consumption. So we assume that: $g_{1}\left(r_{1 t}^{e}, \delta_{1 t}^{e}\right)=g_{2}\left(r_{2 t}^{e}, \delta_{2 t}^{e}\right)=g\left(r_{t}^{e}, \delta_{t}^{e}\right)$.

Then equation (18) and (19) can be written as:

$$
\begin{aligned}
& g\left(r_{t}^{e}, \delta_{t}^{e}\right) \text { inco }_{1 t}=-f_{1}\left(r_{1 t}^{e}, \delta_{1 t}^{e}\right) \text { fpr }_{t}+\left(\text { cons }_{1 t}-c_{10}-e_{1 t}\right) \\
& g\left(r_{t}^{e}, \delta_{t}^{e}\right) \text { inco }_{2 t}=-f_{2}\left(r_{2 t}^{e}, \delta_{2 t}^{e}\right) f \text { fpri }_{t}+\left(\text { cons }_{2 t}-c_{20}-e_{2 t}\right)
\end{aligned}
$$

Equation (22) is obtained by subtracting equation (21) from equation (20):

$$
\Delta \text { inco }_{t}=\frac{f_{2}\left(r_{2 t}^{e}, \delta_{2 t}^{e}\right)-f_{1}\left(r_{1 t}^{e}, \delta_{1 t}^{e}\right)}{g\left(r_{t}^{e}, \delta_{t}^{e}\right)} f p r i_{t}+\frac{\Delta \text { cons }_{t}-\Delta c_{0}-\Delta e_{t}}{g\left(r_{t}^{e}, \delta_{t}^{e}\right)}
$$

Here, $\Delta i n c o_{t}=i n c_{1 t}-i n c o_{2 t}$ stands for the gap of wealth, we can see clearly that gap of wealth is greatly influenced by wealth effect when we make some subtractions. Then we get conclusion 3 according to equation (22):

Conclusion 3: The relationship between the gap of wealth and housing price depends on the housing wealth effect difference, $f_{2}\left(r_{2 t}^{e}, \delta_{2 t}^{e}\right)-f_{1}\left(r_{1 t}^{e}, \delta_{1 t}^{e}\right)$.

\section{Results and discussions}

\subsection{Dynamic model of housing wealth effect and some extended analysis}

According to consumption function equation (12)

$$
c_{t}=\frac{A_{t}}{\sum_{\tau=0}^{\infty}\left[\pi_{t}\left(1+r_{t+\tau}\right)^{-\tau}\right]}+\frac{\sum_{\tau=0}^{\infty}\left[\left(1+r_{t+\tau}\right)^{-\tau} w_{t+\tau}\right]}{\sum_{\tau=0}^{\infty}\left[\pi_{t}\left(1+r_{t+\tau}\right)^{-\tau}\right]}+\frac{\pi_{t} \bar{c}-\bar{c}}{\pi_{t}}+\mu_{t}
$$


Coefficient of wealth in the consumption function is a variable value. The unstable coefficients are decided by $\pi_{t}$ and $\sum_{\tau=0}^{\infty}\left(1+r_{t+\tau}\right)^{-\tau}$. That is to say, the consumption coefficient of period $t$ depends on the rate of subjective time preference of period $2 t\left(\delta_{2 t}\right)$ and the lifetime real interest rate. In conclusion, we can say that current consumption is under the influence of the expected rate of subjective time preference and expected real interest rate.

Extending the housing wealth effect model, we get another form of the housing wealth effect equation:

$$
f\left(r_{t}^{e}, \delta_{t}^{e}\right)=\frac{\text { cons }_{t}}{\text { fpri }_{t}}-\frac{c_{0}}{f p r i_{t}}-g\left(r_{t}^{e}, \delta_{t}^{e}\right) \frac{\text { inco }_{t}}{\text { fpri }_{t}}-\frac{e_{t}}{\text { fprit }}
$$

a. If $f\left(r_{t}^{e}, \delta_{t}^{e}\right)>0$, the housing wealth effect is positive and it increases or decreases along with the increase or decrease of the housing price-to-income ratio. So when income is a constant and the housing price is low, a proper increase in housing price is good for stimulating consumption and enlarging domestic demand. While when the housing price is high, it is unwise to enlarge domestic demand by making use of the positive impact of housing wealth effect, because although a further increase in housing price can stimulate domestic consumption, it may also bury the seeds of the housing bubble.

b. If $f\left(r_{t}^{e}, \delta_{t}^{e}\right)<0$, the housing wealth effect is negative, and it increases or decreases in inverse proportion to that of the housing price-to-income ratio. So when income is a constant and the housing price is low, a proper increase in housing price is good for reducing the negative impact of housing wealth effect and may help to relieve some of the "squeeze effect" of housing price on consumption. Similarly when the housing price is high, it is not appropriate to use housing wealth effect as an index to decide whether to raise the housing price.

\subsection{Influence of economic inequality on housing wealth effect}

According to economic inequality formula

$$
\Delta \text { inco }_{t}=\frac{f_{2}\left(r_{2 t}^{e}, \delta_{2 t}^{e}\right)-f_{1}\left(r_{1 t}^{e}, \delta_{1 t}^{e}\right)}{g\left(r_{t}^{e}, \delta_{t}^{e}\right)} f p r i_{t}+\frac{\Delta \text { cons }_{t}-\Delta c_{0}-\Delta e_{t}}{g\left(r_{t}^{e}, \delta_{t}^{e}\right)}
$$

Assume $d_{t}=f_{2}\left(r_{2 t}^{e}, \delta_{2 t}^{e}\right)-f_{1}\left(r_{1 t}^{e}, \delta_{1 t}^{e}\right)$, then equation (22) is turned into

$$
\Delta \text { inco }_{t}=\frac{d}{g\left(r_{t}^{e}, \delta_{t}^{e}\right)} \text { fpri }_{t}+\frac{\Delta \text { cons }_{t}-\Delta c_{0}-\Delta e_{t}}{g\left(r_{t}^{e}, \delta_{t}^{e}\right)}
$$

a. If $d_{t}>0$, housing wealth effect of the poor is larger than that of the rich and the economic inequality rises or declines in direct proportion with the rise and decline of housing price. The relative wealth change of the poor is bigger, which makes them willing to spend more to satisfy their consumption demands. As for the rich, the rise of housing price does not make much difference. The relative wealth change is rather small and they do not have the impetus to increase their consumption. Under this circumstance, with a further increase of housing price, the gap between the poor and the rich is widen.

b. If $d_{t}<0$, housing wealth effect of the rich is larger than that of the poor and the economic inequality increases or decreases in inverse proportion with that of the housing price. At this time, the poor are cautious about the economic situation and less willing to increase 
their consumption. In this way, with the further increase of the housing price, the gap between the rich and the poor is diminishing.

Our analysis shows that the inequality $\Delta i n c o_{t}$ changes with housing price, and the relationship between economic inequality $\Delta$ inco $_{t}$ and housing price $\mathrm{fpri}_{t}$ is affected by the difference of housing wealth effect between the rich and the poor $d_{t}$. If $d_{t}>0$, economic inequality and housing price change in the same direction; if $d_{t}<0$, economic inequality and housing price change in opposite directions.

\section{Conclusions}

We got three interesting conclusions: 1) Housing wealth effect is a dynamic process. 2) The housing price-to-income ratio is a crucial factor in housing wealth effect. 3) The relationship between wealth gap and housing price depends on the housing wealth effect differences.

\section{Acknowledgment}

The authors wish to acknowledge the support of National Natural Science Foundation of China (Project No. 71203217 and No. 71173213 ) and China Postdoctoral Science Foundation (Project No. 2012T50151 and No. 2011M500412).

\section{References}

[1] Hall R E. Stochastic implications of the life cycle-permanent income hypothesis: Theory and evidence. Journal of Political Economy, 1978, 86(6): 971-987.

[2] Carroll C D, Otsuka M, Slacalek J. How large are housing and financial wealth effects? A new approach. Journal of Money, Credit and Banking, 2011, 43(1): 55-79.

[3] Aron J, Duca J V, Muellbauer J, et al. Credit, housing collateral, and consumption: Evidence from Japan, the UK, and the US. Review of Income and Wealth, 2012, 58(3): 397-423.

[4] Wu D, Gao P, Dong J C. Research for the demand of housing in Chinese cities based on the theory of scenes. Journal of Systems Science and Mathematical Sciences, 2011, 31(3): 253-264.

[5] Wu D, Gao P, Dong J C. Impact of subsidy on low-rent housing lessees' welfare in China. International Journal of Information Technology \& Decision Making, 2012(3): 643-660.

[6] Wu D. The research on urban residential choice and housing price's spatial difference in China: Based on the theory of scenes. Economy \& Management Publishing House, Beijing, 2013. 